\title{
HEALTH CENTER NEEDS MANAGER WITH GRADUATE OF PROFESSION OF PUBLIC HEALTH GENERALIST IN INDONESIA
}

\author{
Buchari Lapau \\ Professor of Public Health/Epidemiology, Master of Public Health Education Program, \\ Pekanbaru Institute of Health Sciences Hang Tuah (STIKes HTP) Riau, Indonesia.
}

\section{Alib Birwin}

Lecturer of Epidemiology, Bachelor of Public Health Education Program, School of Health Sciences, University of Haji Abdul Malik Kamarullah (UHAMKA), Jakarta, Indonesia

\section{Tamri}

Lecturer of Public Health Administration and Policy, Bachelor of Public Health Education Program, School of Health Sciences University of Respati Indonesia (URINDO), Jakarta, Indonesia

\begin{abstract}
An additional cost of health insurance paid by the government has increased every year. Theoretically, this is due to curative services have been more and more dominant. The one problem might be due to different views between 2 organizations concerning public health. The objective of this paper is offering innovative thought to create the same view between the 2 organizations to strengthen preventive and promotional health services through health centers. One organization has conducted competency examination to Bachelor of Public Health Specialist; if he/she passes the examination, they are granted a Letter of Registration. However, another organization disagrees, because someone will obtain a Letter of Registration if he/she has already passed as a Profession of Public Health. Concerning with the different view, the writers offer an Innovative Thoughts that necessary Profession in Public Health Generalist appointed to be Manager in Health Center, for which Profession of Public Health Generalist Education Program established, where students receive theory in class and practice in the Field Laboratory of Public Health based on Integration of Public Health Scientific Disciplines. The government should also provide the Profession of Public Health Specialist working in the functional position in the Ministry of Health and Provincial/District Health Department. The writers formulate several conclusions to strengthen preventive and promotional health services enhancing community health status as the one factor to develop human resources namely Presidents Joko Widodo's Vision in the Second Working Cabinet 2019-2024.
\end{abstract}

Keywords: the profession of public health generalist, health center, manager, integration, scientific disciplines 
Cite this Article: Buchari Lapau, Alib Birwin, Tamri, Health Center Needs Manager with Graduate of Profession of Public Health Generalist in Indonesia, International Journal of Management, 10 (6), 2019, pp. 8-19. http://iaeme.com/Home/issue/IJM?Volume $=10 \&$ Issue $=6$

\section{INTRODUCTION}

Health Centers (HC) have been established since 1968, and in 1974 there appeared Instruction of President (Inpres) concerning HC establishment and Water Supply \& Latrine (WSL) installation in Indonesia. Health centers should focus on prevention and promotional health services, although there is a simple curative health service, and if it is necessary the patients are referred to hospital (Lapau, 1987). In fact, the dominant curative services cannot be avoided because theoretically preventive and promotive health services have not been successful to decrease morbidity rates. In the era of Reformation, the domination of curative services more and more increase which causes the government has to pay the additional costs for health insurance increase every year ${ }^{(a)}$.

It means that more than 50 years after the health center established, prevention and promotion health services have not been successful in Indonesia.

Hippocrates, the father of medical sciences who lived 4 century before Masehi in the era of Greeks was frustrated to solve the problem of patients' visits more and more to his hospital. Then Hippocrates considers that the causes of diseases are factors in the human body and environmental factors (Lapau and Birwin, 2017). Afterward, the attention of medical sciences increased to control environmental factors to decrease the occurrence of diseases. Based on the development of epidemiology producing information useful for environmental control, in the 19th-century public health sciences appeared. School of Public Health started appearing in Germany and England (Gordon, 1953b). Public Health developed in the USA where Winslow defined public health in 1920 (AAPHP, 2011). Between the year of 1950 and 1960, lecturers of the School of Medicine from Indonesia learned public health in England and the USA. It followed by the establishment of the Department of Public Health in School of Medicine, University of Indonesia $^{(b)}$ In 1965 for the first time, the School of Public Health established at the University of Indonesia (Lapau 1983).

At the end of the 20th century appeared the idea to establish the Profession of Public Health Education Program which is one level higher than the Bachelor of Public Health Education Program. ${ }^{\text {(c) }}$ However, in 2008 Indonesian Public Health Association (IPHA) held meeting to declare the establishment of Indonesian Public Health Collegium Committee (IPHCC) consisting of several colloquiums by scientific discipline of public health such as epidemiology, health administration and policy, health promotion, environmental health, occupational health, public health nutrition, and reproductive health. The objective of IPHCC is to produce the Profession of Public Health Education Progam by scientific disciplines. At that time, each collegium chose its chairman. From 2008 to 2011 several meetings were held from one city to another city in Indonesia, but IPHCC had not been successful to create the concept of Profession of Public Health Education Program. ${ }^{(d)}$

At the present time, there are 2 organizations concerning public health namely the Indonesian Public Health Association (IPHA) and Indonesian Bachelor \& Profession of Public Health Association (IBPPHA). IPHA stated establishing on 22 February 1971(IAKMI, 2019). The member of IPHA consists of 1) Bachelor of Public Health originated from high school, Diploma of Nursing, Diploma of Midwife, Diploma of Environmental Health, and other Diploma; 2) Master of Public Health graduated from home country and abroad, and 3) Doctor of Public Health graduated from home country and abroad. As mentioned above, IPHA which declare IPHCC in 2008 was not successful to formulate the concept of Profession of Public 
Health by scientific discipline of public health. However, IPHA and Human Resource Development Board belong to the Ministry of Health have established an organization that has the authority to conduct competency examination to those with Bachelor of Public Health Specialist, and if he/she passes in the examination, he/she is granted Letter of Registration (LoR). Based on this LoR he/she will be legally to work in government and private offices. ${ }^{(\mathrm{e})}$

Indonesian Bachelor and Profession of Public Health Association (IBPPHA) established on 29 October 2019 (PERSAKMI, 219). The IBPPHA would like to establish the Profession of Public Health and considers that someone will be granted a Letter of Registration (LoR) if he/she is a graduate of Profession of Public Health Education Program, no graduate from Bachelor of Public Health Specialist Education Program (PERSAKMI, 2019).

The objective of this present paper is to offer innovative thought for the same view among IPHA, IBPPHA, and Indonesian College/University concerning the Public Health Association (ICUPHA) to strengthen prevention and promotional health services for the increase of community health status in the working area of health centers.

\section{METHOD}

This paper is written based on information from a resource person as the first author having experience as a student, lecturer, active in the organization of university and college concerning public health. In addition, information obtained from television and relevant references. Based on the information, the writers write discussions useful to formulate a conclusion.

\section{BACHELOR OF PUBLIC HEALTH SPECIALIST}

There has been a Bachelor of Public Health specialist consisting of Group A and Group B in Indonesia. The education duration of Group A is 8 semesters, and Group B is 5 semesters. Group A accepts students from high school, and Group B accepts students from diploma programs (3 years after high school) of nursing, midwife, etc. A study conducted to review Bachelor of Public Health Specialist Education Program, Institute of Health which is considered to represent all bachelor of public health specialist in Indonesia because of all such program regulated by the one organization namely Indonesian Public Health University/College Association (IPHU/CA) (Bachelor of Public Health, 2017). The results of the review are as follows:

\subsection{Bachelor of Public Health Program of Group A}

From Semester I to Semester IV, students are given lessons in general public health 74 -semester credit unit (SCU), supportive lessons (14 SCU) consisting of religion, development administration, Indonesian language, English language, basic of medical science 1, business \& entrepreneur, and basic of medical science 2. From Semester V to Semester VI, students are given special lessons by scientific disciplines of public health namely environmental health, health promotion, occupational health and safety, hospital management, public health nutrition, health administration and policy, epidemiology, and reproductive health (43 SCU). In Semester VII, students conduct field practice, where students work together without using integrated public health disciplines (6 SCU). In Semester VIII, students conduct the practice of dedication to the community ( $3 \mathrm{SCU}$ ) and complete research to write a bachelor mini-thesis (4 SCU).

\subsection{Bachelor of Public Health Program of Group B}

From Semester I to semester II, students are given lessons on general public health (47 SCU), and supportive lessons (7 SCU) consisting of public speaking, business, and entrepreneur, and English language. From Semester III and Semester IV, students are given special lessons by scientific discipline of public health (45 SCU). In Semester V, students conduct the practice of 
dedication to the community ( $3 \mathrm{SCU}$ ) and complete research to write a bachelor mini-thesis (4 SCU).

The information mentioned above clarifies that by 2019, university and/or college in the health field just produce Bachelor of Public Health Specialist, no Profession of Public Health in Indonesia.

\section{THE INTEGRATION MODEL OF PUBLIC HEALTH SCIENTIFIC DISCIPLINES}

Experts with either bachelor, master, or doctor in public health should have the capability as Manager (M), Innovator (I), Researcher (R), Analyst (A), Communicator (C), Leader (L), and Educator (E), which are abbreviated to be MIRACLE. In this case, Epidemiology represents Innovation (I), Research (R), and Analysis (A); Health Administration and Policy represent Management (M), and Leader (L); and Health Promotion represents Communication (C), and Education (E) (Lapau, 2019).

The roles of the scientific discipline of epidemiology are 1) to diagnose health problems especially communicable and non- communicable diseases; 2) to identify the natural history of diseases and the cause of diseases, and 3 ) to produce information useful to the management of health services and health program (Lapau and Birwin, 2017). The cause of certain diseases may be related to the problem in the scientific discipline of health administration and policy and the scientific discipline of health promotion concerning health behavior. The problems in both disciplines are indirectly affecting the occurrence of communicable and noncommunicable diseases through the problems in the four scientific disciplines namely environmental health, occupational health and safety, public health nutrition, and reproductive health. In this case, epidemiology identifies relevant factors concerning each of the 6 other scientific disciplines of public health.

Methodology and technology of scientific discipline of health administration and policy can be stated in the form of administration, management, and health policy. Administration means delivering services (Azrul, 1993). Management is a nucleus of administration regulating the action of services (Fitri, 2012). The policy is a scientific discipline in applied social sciences using various research methodology and arguments producing relevant information to formulate recommendation which is useful in the level of decision making to solve certain problems (Suyoto dan Supriyanto, 2015). Administration and management of the health center are to deliver public health services by the leadership of the Head of Health Center through the managers of epidemiological surveillance, programs of health promotion, communicable disease control, non-communicable disease control, occupational health and safety, public health nutrition, maternal and child health, and family planning. Logically, the Head of Health Center will be successful to lead health centers if he/she is trained in the field laboratory to use all public health disciplines integrated; his/her successfulness is questionable if he/she is a specialist only in health administration and policy. When the policy of decentralization has been confirmed in Indonesia to the district level since the year 2000 (Utama, 2005), the district health department has had the authority to confirm health policy. Therefore, the Head of the Health Department should have the competency to formulate health policy proposed to the Head of District Government and Parliamentary who will decide political decision. In this case, it is necessary to have the Head of the District Health Department who was trained in the field laboratory of public health, where he/she has the experience to practice all public health disciplines integrated. It means that he/she should have a degree as a profession of public health generalist.

Methodology and technology of discipline of health promotion practically through health promotion program consisting of 2 health activities namely 1) health education to one 
individual or a group of individuals which is useful to promote community health, and 2) interprogram advocation and inter-sector advocation: Inter-program advocation is to use the method or technique of discipline of health promotion integrated with to solve the relevant problem in health programs concerning the disciplines of environmental health, occupational health, public health nutrition, or reproductive health. Inter-sector advocation is to use the method and technique of health promotion to cooperate with relevant sectors outside of the health department (such as the agricultural sector, education sector, etc) to solve certain problems.

Methodology and technology in the scientific discipline of environmental health practically through environmental health programs to solve the problem of relevant diseases such as tuberculosis, acute respiratory infection, pneumonia, diarrheal diseases, hemorrhagic fever, malaria, etc. Methodology and technology in the scientific discipline of occupational health and safety practically through occupational health programs to solve the problems of occupational accidents, hearing, eyesight, skin diseases, etc.

Methodology and technology in the scientific discipline of public health nutrition practically through public health nutrition program to solve the problem of disease related to nutrition such as malnutrition, kwashiorkor, obesity, etc. Methodology and technology in the scientific discipline of reproductive health practically through maternal and child health $(\mathrm{MCH})$ program to solve the problem such as pregnant anemia, etc, and family planning program to plan birth rate creating welfare

The role of the scientific discipline of epidemiology in the integration of public health scientific disciplines is to formulate intervention of solving problems especially diseases indirectly through health administration and policy, and health promotion; and to formulate intervention of solving problems especially diseases directly through scientific disciplines and programs of environmental health, occupational health, public health nutrition, and reproductive health, as shown in the following model.

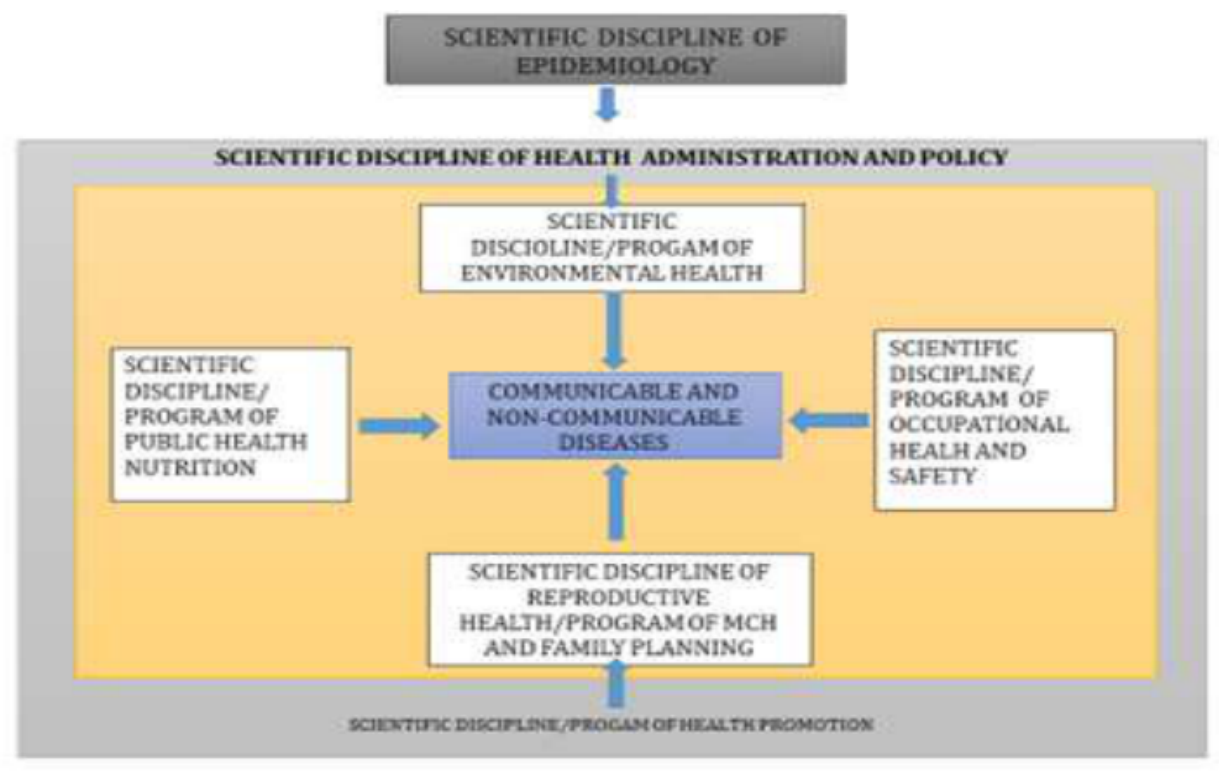

Figure 1

The Integration Model of Public Health Scientific Disciplines

As a conclusion, epidemiology does not implement the intervention. However, epidemiology provides information useful in the MIRACLE by health administration and policy namely management, policy and leadership, and by health promotion, namely health 
communication and advocation through the 4 (four) disciplines/program) namely environmental health, occupational health, public health nutrition, and reproductive health/MCH \& Family Planning. All scientific disciplines of public health integrated to formulate and conduct the intervention enhancing community health status.

\section{FIELD LABORATORY OF PUBLIC HEALTH}

The development of medical science consists of 4 steps namely 1) diagnosis of disease is based on symptoms and signs of disease; 2) finding and progress in microbiology create diagnosis of disease based on the cause of disease; 3 ) development of specialization in medical science; and 4) the need for field laboratory solving health problem (Barton, 1971).

Since 2011 public health education in the USA has been established to produce scientific practitioners in public health movement; in this case, the teaching involves a combination of public health science disciplines to produce graduates having competency in practice and research. It means that public health education consists of a lecture in class and practice in the field laboratory involving a combination of public health disciplines (AAPHP, 2011).

In the meeting held in the Faculty of Public Health University of Indonesia before 1989 appeared the desire to establish the Laboratory of Epidemiology and Management in the working area of health center level; this desire appeared because epidemiology and management are useful for health planning. The goal of laboratory establishment is to obtain information useful to defend and enhance the capacity to prevent and avoid the appearance of health problems. To achieve the goal, it is also necessary for the role of other public health disciplines. As a consequence 8 objectives of the laboratory formulated (Lapau, 1989), which become an inspiration for the next development of field laboratory.

Indonesia has developed and implemented the Indonesian Qualification Framework (IQF) consisting of 9 levels (Dikti, 2011). The 6th level of IQF is a qualification for Bachelor of Public Health having the following competencies namely 1 ) adapting with situation useful to solve health problems; 2) finishing procedural problems; 3) making a decision based on the result of data analysis, and 4) creating an indication of various alternatives of solution. The Bachelor of Public Health graduate may have a position one level under manager which is called submanager. The 7th level of IQF has 3 competencies namely 1) managing health resources under of his/her authority comprehensively by using scientific knowledge and technology producing steps for strategic development of organization; 2) solving health problems scientifically and technologically, and 3) conducting research and make strategic decision accountably, and fully responsive on all aspects under his responsibility. After graduation, he/she will be a manager of a health program at the health center, and after several years, he will be the manager and head of a health center.

We define the Field Laboratory of Public Health is the working area of health center or District/Municipality Health Department, where students and lecturers work to practice integration of public health science disciplines producing information useful to formulate health policy and management concerning health services/program; students and lecturers of Bachelor and Profession of Public Health, Master and Doctor of Public Health Education Program practice and conducting research in the working area of health center, while students and lecturers of Master and Doctor of Public Health Education Program practice and conducting research in the working area of District/Municipality Health Department.

The reasons for establishing the field laboratory of public health (Lapau, 2018) are as follows:

- There is the gap between theory given by the institute of public health education and the practice of theory in the field. If there is cooperation between the institute of public health education and facilities of health services, the gap could be solved. 
- Since there has been a policy of decentralization in district/municipality levels, the health department has the authority to decide the policy and management of health services in its working area. To decide policy and management, it is necessary to conduct studies in the field laboratory of public health.

- Indonesia consists of many large and small islands occupied by citizens having different cultures, and social-economic status which affects the utilization of health services. Therefore, health policy at the central level may not be applied to a certain local level. Health policy in a certain district should be based on the result of the study in the district concerned.

- The location of public health education belongs to university or college reach provinces even districts/municipalities. Therefore, cooperation between universities/colleges having public health education and district/municipalities health department including health centers should be created so that various problems in the area concerned could be solved. It does not mean that it is necessary to give a lecture on health programs. However, lecturers and students need to study health programs that are relevant to their studies.

- Since the first cabinet led by President Joko Widodo has modified the Ministry of High Education to be the Ministry of Research \& Technology and High Education, it means that information from Master Thesis and Doctor Dissertation should be useful to formulate health policy in the central and local governments. Thus if there is cooperation between university/college studying health and district/municipality health department including health centers, information from Master Thesis and Doctoral Dissertation could be useful to formulate health policy and health management improvement at the district/municipality concerned.

\section{THE PROFESSION OF PUBLIC HEALTH GENERALIST EDUCATION PROGRAM}

The proposed Profession of Public Health Generalist Education Program is equivalent to the Medical Profession Education Program running for 6 years. In the first and second-year students are given lessons on the theory and practice of the preclinical group. In the third year, students are given lessons on the preclinical group and start being given a small clinical group. In the fourth year, students are given theory and practice of lessons concerning clinical group, and so on until the fifth and sixth year.

Thus it is proposed Profession of Public Health Generalist from Semester I to Semester IV, students are given lessons on general public health (74 SCU) and supportive lessons (14 SCU): as proposed integration of public health disciplines, in Semester III students are given lessons on data management (2 SCU) concerning health programs from Ministry of Health; in Semester IV students are given lessons on epidemiological surveillance (3 SCU) as continuation of lessons on data management given in Semester III. In Semester V to Semester VI students are given lessons on special public health by public health disciplines (43 SCU): based on the certain problems found by epidemiological surveillance in Semester IV, in Semester V students conduct observation to the field to find information useful to formulate intervention (2 SCU) solving the certain problems by each of other relevant public health disciplines; in Semester VI students conduct intervention ( $2 \mathrm{SCU}$ ) solving the certain problems to the field, and collecting, analyzing, and interpreting data to produce information to formulate more corrected intervention; in Semester VII students conduct and evaluate intervention (2 SCU) based on formulation in Semester VI. Some or all lessons given for specialists in Semester V and Semester VI may be useful to solve the problems found in Semesters IV, V and VI. In Semester VIII, students conduct and write a report on the intervention of dedication to the community (3 SCU) at Institution outside of the health center and write a research proposal and write a report of Bachelor Mini Thesis.

If the government decides to establish the Profession of Public Health Generalist, at the beginning from Semester IX to Semester X, students are given lessons on managerial 
epidemiology, several lessons on other management such as quality management, management strategy, leadership, and communication \& advocation. Then several groups of students practice managerial epidemiology to monitor and evaluate certain health programs related to scientific disciplines of environmental health, public health nutrition, and reproductive health, and occupational health and safety to some extent in a health center. Furthermore, in the evaluation and planning of health program, each group of students conducts research integrated with the practice of managerial epidemiology, quality management, and communication \& advocation. Each student presents his/her scientific paper in a seminar in class, health center, and other places.

\section{DISCUSSION}

Comprehensive health services consist of curative, preventive, promotional, and rehabilitative health services. Essential public health services through the health center are preventive and promotional health services. In Indonesia, health centers have been established since 52 years ago, and Faculty of Public Health has been established since 54 years ago, starting from University of Indonesia (UI), then they were extended to University of Airlangga (UNAIR), University of Gajah Mada (GAMA), University of Sumatra Utara (SUMUT), University of Diponegoro (UNDIP), and University of Hasanuddin (UNHAS). In addition at least 160 Public Health Education Programs belong to the College of Health that had been established until 2010. However, preventive and promotional health services have not been successful yet. As a consequence curative health services increased as the one to cause annual additional cost paid by the government for health insurance every year. The failure of preventive and promotional health services through health centers might be due to 1) no effective cooperation between public health education programs belong to university/college of health and public health services; 2) public health education programs belong to university/college of health only produce Bachelor of Public Health Specialist; 3) students have no experience to work in the field laboratory of public health based on integration of public health disciplines.

Health center is the foremost health services administration directly contact with the community. If the profession of general physician (generalist) mastering all medical disciplines to diagnose and treat disease individually by superficial competency, thus it is also necessary the existence of profession of public health generalist as a manager in a health center belong to the government, who are able to integrate all public health disciplines to diagnose community health problem and formulate intervention solving the problem in the working area of health center. Thus it is necessary to establish Profession of Public Health Education Program (item E) where lessons are given in class and the Field Laboratory of Public Health (item D) based on Integration of Public Health Disciplines (item C). Hopefully, this effort enhances preventive and promotional health services through the health center.

There was informal information that meeting has occurred among Indonesian Public Health Association (IPHA), Indonesian Bachelor and Professional of Public Health Association (IBPPHA), and Ministry of Research \& Technology and High Education (MRTHE) to talk about competency examination: IPHA has conducted examination for Bachelor of Public Health Specialist Graduates, when they pass examination they are given Letter of Registration (LoR), while IBPPHA disagrees with this competency examination because IBPPHA believe that only Profession of Public Health Graduates who are appropriate to obtain the LoR. The important decision of this meeting is that it is necessary to establish the Profession of Public Health Education Program. After the meeting, IPHA established the Indonesian Public Health Collegium Committee (IPHCC) consisting of several collegiums by public health disciplines as it was established and developed from 2008 to 2011. Each collegium designs the concept of professional education to produce Profession of Public Health Specialist namely Professions of 
Epidemiology, Health Administration and Policy, Health Promotion, Environmental Health, Occupational Health and Safety, Public Health Nutrition, and Reproductive Health. Such a kind of public health specialist is suitable to work for a functional position in the Ministry of Health, Provincial Health Department, and District/Municipality Health Department. However, If we just establish Profession of Public Health Specialist Education Program, this decision invites anxiety: If we consider that public health is a mother, while epidemiology, ....., etc are children, the mother (public health) will be disappeared, and children (epidemiology,.... etc) would not know who is their mother. To solve the problem of anxiety, we should establish the Profession of Public Health Generalist Education Program producing Profession of Public Health Generalist who is suitable to work as a manager in a health center.

Bachelor of Public Health Generalist Education Program accepts students who have passed high school. After graduating as Bachelor of Public Health Generalist, he/she may continue his/her study two semesters more to be Profession of Public Health Generalist, who are appropriate given Letter of Registration (LoR). Bachelor of Public Health Specialist Education Program accepts a student who graduates from the Diploma Program of environmental health, nursing, midwifery, and other Diploma Program. The graduate of Bachelor Specialist may continue his/her study to the Profession of Public Health Specialist. After graduating from the Profession of Public Health Specialist Education Program, he/she may be given a Letter of Registration (LoR).

Based on information mentioned above actually it is not necessarily more different view among IPHA, IBPPHA, and Association of University/College of Public Health (IAUCPH): IPHA through Indonesian Public Health Collegium Committee (IPHCC) designs Profession of Public Health Specialist Education Program, IBPPHA designs Profession of Public Health Generalist Education Program, and IAUCPH should arrange curriculum of Profession of Public Health Generalist and Specialist Education Program.

The firs out of 5 visions of the Second Cabinet 2019-2024 led by the President of Ir. Joko Widodo is the development of human resources. If the Program of Public Health Generalist and Specialist Education Program established, they will produce Profession of Public Health Generalist and Specialist, who are able to enhance preventive and promotional health services, curative health services will decrease, additional cost for health insurance paid by the government will decrease, and community health status will increase, so that community welfare will be realized. As a consequence, human resources in all sectors will be more productive, the development in all sectors will be more successful in the Second Working Cabinet led by President Ir. Joko Widodo. Therefore, the government should decide policy to establish the Profession of Public Health Generalist and Specialist Education Program in universities and colleges of health.

According to the writers, what has been written above is innovative thought for the nation even at the international level. However, readers may disagree. Therefore, the writers are pleased to have a constructive critique. If the readers agree, let us hold a seminar and/or workshop to develop the thought more operational and realize health development to enhance Indonesian health status.

\section{CONCLUSION}

1. The Profession of Public Health Generalist is appropriate to be a manager in the health center to diagnose and solve community health problems in the working area of the health center.

2. Indonesian Public Health Association through Indonesian Collegium Public Health Committee should design Profession of Public Health Specialist Education Program in class and field laboratory; Indonesian Bachelor and Profession of Public Health Board should design Profession of Public Health Generalist Education Program (see item E) in class and field 
laboratory of public health (see item D) based on integration of public health scientific disciplines (see item $\mathrm{C}$ ).

3. The mother (public health) will not be disappeared, and children (public health scientific disciplines such as epidemiology,........., etc) will not forget her mother when the government makes the decision to establish the Profession of Public Health Generalist Education Program.

4. The Profession of Public Health Specialist Education Program accepts students having a diploma degree in health, producing Profession of Public Health Specialist who directly given LoR to work in a functional position in Ministry of Health, Provincial Health Department, and District/Municipality Health Department.

5. The profession of Public Health Generalist Education Program accepts students already passed from high school, producing Profession of Public Health Generalist who is directly given LoR to have the position as manager in a health center.

6. National health development in the Republic of Indonesia, need to unify view among Indonesian Public Health Association (IPHA), Indonesian Bachelor and Profession in Public Health Association (IBPPHA), and Indonesian Association of University and College of Public Health in Indonesia (IAUCPH) to enhance community health status and welfare in Indonesia: IPHA through Indonesian Public Health Collegium Committee (IPHCC) designs Profession of Public Health Specialist Education Program, IBPPHA designs Profession of Public Health Generalist Education Program, and IAUCPH arrange curriculum for Profession of Public Health Specialist and Generalist.

7. It is necessary cooperation between Ministry of Research \& Technology and High Education with Ministry of Health to formulate policy on cooperation between Institute of Public Health Education Program and District/Municipality Health Department to establish Field Laboratory of Public Health based on Public Health Scientific Discipline Integration producing information useful to formulate health policy and management enhancing community health status and welfare in district/municipality in Indonesia.

8. It is necessary cooperation between the Ministry of Research \& Technology and High Education with the Ministry of Health to formulate policy on the establishment of the Profession of Public Health Generalist and Specialist Education Program.

9. The Profession of Public Health Generalist and Specialist enhance the success of preventive and promotional health services, decrease curative services, decrease additional cost for health insurance annually paid by the government, increase community health status, which is necessary for the essence of human resources development, the first vision of President Joko Widodo leading the Second Cabinet of Indonesian Republic 2019- 2024.

\section{KEYNOTES}

(a). An Information heard by Buchari Lapau in Metro TV and other televisions from 2016 to 2019

(b) When Buchari Lapau was a student in the Faculty of Medicine University of Indonesia starting in 1958, he heard that lecturers of medical school had studied public health in the USA.

(c). At the end of the 20th century, Buchari Lapau was the Dean of Faculty of Public Health, University of HAMKA; he was invited by the President of the Indonesian Public Health Association to attend the Meeting on Planning of Establishment of Profession of Public Health Education Program.

(d). In March 2008 Buchari Lapau attended the meeting to declare the establishment of Indonesian Public Health Collegium Committee, and Buchari Lapau was elected and appointed as Chairman of Epidemiology Collegium 
(e) This information has been existing since 2011

\section{REFERENCES}

[1] Association of Accredited Public Health Progam (AAPHP), Public Health Resources. www.aaphp.org/public health resource.html. 2011

[2] Azrul, Azwar, Introduction to Health Administration, Third Edition, Tangerang: Bonepura Aksara, 1993

[3] Bachelor of Public Health, Academic Manual Book Pekabaru: STIKes HTP, 2017

[4] Barton, WI, The development of medical science, Health Planning Course Implemented by Institute of National Health, July 1971.

[5] Directorate General of High Education, Indonesian Qualification Framework. A Study on Implication and Study on IQF, Jakarta: IQF, 2011

[6] Fitri, Arini, The relation between Administration and Health Administration, Organization, and Health Policy, Makasar: FKM UNHAS, 2012

[7] Gordon, Evolution of Epidemiology of Health II. Five High Roads of Epidemiology. - From the 17th Century to Present Day. The Epidemiology of Health ed Iago Goldstone, New York: Health Education Council, 1953, pp 40-60.

[8] IAKMI, Basic Regulation of Indonesian Public Health Association www.iakmi.or.id, 2019

[9] Lapau, Buchari, Effort Institutionalization and Professionalization Trough Transpolitization - A Case Study on the Development Plan of Department of Epidemiology Faculty of Public Health University of Indonesia, Medika no. 8 Tahun 9, 1983

[10] Lapau, Buchari, Treatment Seeking Behavior in Lilirilau Subdistrict, South Sulawesi, Indonesia a Dissertation for Doctor Degree in Public Health presented on 29 March, 1989at the Hall Faculty of Medicine University of Indonesia, Jalan Salemba 6 Jakarta, 1987

[11] Lapau, Buchari, Several Academic Activities Related to Health Development, A Review on Epidemiology Evolution, a Speech Mentioned at the Inauguration as Professor of Epidemiology in 16. Faculty of Public Health Univesity of Indonesia on 29 March 1989 at the Hall of Medical Faculty Univesity of Indonesia, Jalan Salemba Raya 6, Jakarta, 1989

[12] M.A. Shanti, K. Saravanan, An Effect of Data Mining Techniques in Public Healthcare- A Case Study. International Journal of Civil Engineering and Technology, 9(9), 2018, pp. 115122

[13] Lapau, Buchari and Alib Birwin, Principle and Method of Epidemiology, Depok: Kencana Media Group, 2007

[14] Lapau, B and Nyoman Kandun. Field Laboratory of Public Health Based on Epidemiology, a Paper Presented at the Meeting of Field Epidemiology Training Program and Indonesian Epidemiology Association in Yogyakarta in May 2016, 2018

[15] Lapau B, Field Laboratory of Public Health Based On Integration of Public Health Discipline in Brainstorming Seminar held at Hang Tuah Institute of Health in Pekanbaru, Riau in February 2019.

[16] Sumathi G N, Perceived Organizational Support in Indian Rural Public Healthcare Sector, International Journal of Mechanical Engineering and Technology 9(7), 2018, pp. 885-901. 
[17] PERAKMI, Branda Indonesian Bachelor and Profession of Public Health Organization https//persakmi or.id, 2019

[18] PERSKMI, PERSAKMI Matured Profession of Public Health Education Program, https//perakmi.or.id, 2019

[19] Suyoto S and Supriyanto S, Health Policy and Management, Surabaya: Universitas Airlanggaa, 2015

[20] Utama, Surya, To Study Analysis of Health Policy, Medan: Universita Sumatra Utara, 2005 